\title{
Interview with Professor Mark A Wainberg
}

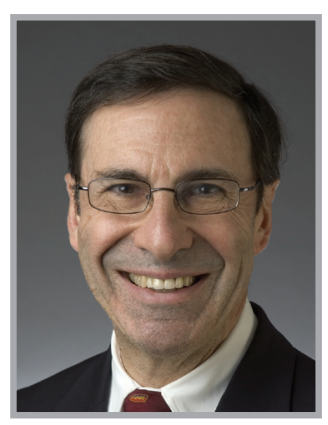

Dr Mark A Wainberg* is Professor of Medicine and Microbiology and Immunology at McGill University (Montreal, Canada) and Director of the McGill University AIDS Centre. He served as President of the International AIDS Society between 1998 and 2000 with responsibilities that included organization of the XIII International Congress on AIDS (Durban, South Africa) in 2000. He was also co-Chair of the XVI International AIDS Conference that took place in Toronto, Canada, in August 2006. He is well known for his initial identification of 3TC as an antiviral drug, in collaboration with BioChem Pharma Inc, in 1989, as well as for multiple contributions to the field of HIV drug resistance. Dr Wainberg now works on efforts to achieve a cure for HIV infection. Among other honors, Dr Wainberg is an Officer of the Order of Canada and a Chevalier in the Legion d'Honneur of France, as well as the recipient of a number of honorary doctorates. Dr Wainberg is an author of over 500 research papers and 100 reviews and commentary articles that have appeared in scientific literature. He is co-Editor-inChief of Retrovirology, co-Editor-in-Chief of Journal of the International AIDS Society, and is a member of the editorial committees of multiple other journals. More than 30 students have obtained their PhD degrees under his tutelage.

First draft submitted: 2 August 2016; Accepted for publication: 10 August 2016; Published online: 30 August 2016

\section{Q Could you briefly summarize your career to date?}

I am best known for the research that I have done with HIV. I began my career as a basic retrovirologist, studying other members of the retrovirus family of viruses that were not associated with HIV. I then transformed myself into a HIV virologist as it became evident that HIV was going to be a very important human pathogen. I was probably the first scientist in Canada who was able to establish a laboratory that was capable of growing HIV. That led us to play an important role with regard to the identification of the drug termed lamivudine as an important antiviral agent. I also played a role as an administrative and political leader in the HIV field because I was elected president of the International AIDS Society. I served in this capacity from 1998 to 2000, during which time I played a lead role in the organization of the International Aids conference that took place in Durban, South Africa, in 2000 and I have tried to continue to do good work for the remainder of the time since then.

\section{Q What is your research currently} focusing on at the McGill University AIDS Center?

We are still very much involved in studies on HIV drug resistance, notably how the virus becomes drug resistant and the importance of that. Right now we are

*McGill University AIDS Centre, Jewish General Hospital, Montreal, Quebec, H3T1E2, Canada; mark.wainberg@mcgill.ca

\section{KEYWORDS}

antiretroviral drugs $\bullet$ costs $\bullet$ generic - HIV • integrase inhibitors 
focused on integrase inhibitors and I think that will remain our main focus.

Q What has your most recent research on integrase inhibitors shown in terms of future antiretroviral therapies to treat HIV?

We and others have shown that HIV is a virus that mutates as it replicates to become drug resistant. For Dolutegravir ${ }^{\odot}$, the newest member of the integrase inhibitor family of drugs, such mutations may not happen to the same extent. This is because we believe it selects for mutations that are very detrimental for virus replication. If this is true we will finally have a drug against which drug resistance may be less likely to happen. If this were the case, I think the implications would be very important.

Q What are the limitations to this treatment? There are always limitations. Some people may not be able to take drugs because of toxicities, other people may not adhere to drug taking for a variety of reasons, but I think in general this is the best drug regimen we have available, so we have reason to be optimistic.

Q Other than integrase inhibitors, are there any other potential HIV inhibitors that are being developed at the moment?

There are a few new drugs; Gilead Inc ${ }^{\odot}$ has one that looks very interesting called Bictegravir ${ }^{\odot}$; the drug that we are working on now is Dolutegravir; Merck Inc has a new drug that is not an integrase inhibitor, it is a reverse transcriptase inhibitor called $\mathrm{EfDA}^{\odot}$ that looks very interesting owing to its ability to perhaps withstand the development of drug resistance.

Q So drug resistance is a big difficulty: what way have you been avoiding this with developing new treatments?

I think the best way is for people to take their drugs very faithfully so that the drugs keep working. If we had a situation whereby a drug was novel in the sense that it did not give rise to drug resistance, I think that would be a huge benefit. Integrase inhibitors so far are the best drugs that we have ever had.

\section{Q What do you think future targets of HIV} inhibitors will be?

People are working towards new categories of HIV drugs; for example maturation inhibitors, which prevent the assembly of the virus, are a hot area and hopefully these drugs will come to fruition as well.

\section{Q You have been involved in research to} prevent HIV infection in developing countries; are these the main areas you are targeting right now?

I think developing countries are where most of the problems that relate to HIV actually reside. There are more new infections in developing countries than in the west; there are more problems of drug resistance in developing countries than in the west. I think partly the reason is because many of the wonderful drugs that are available in the western countries, such as the UK and Canada, including the new integrase inhibitors, are not yet available in developing country settings. This has to change. If we are going to really make the kind of headway in developing counties that we have made in western countries, we cannot continue to treat people in developing countries with drugs that are second rate.

\section{Q Do you think more preventative} techniques could be a better method for reducing the numbers of HIV-infected individuals in developing countries? Well, for sure, we need better prevention modalities. Obviously we need to think more about techniques, such as pre-exposure prophylaxis (PrEP) but I think, as well, we need to make sure the same excellent integrase inhibitors that are used now in the UK, Canada and USA are used across the board to treat patients in South Africa and India and other such venues.

Q Cost obviously being one of the main barriers of this, is there any way you think we could get around this?

I think that the brand name companies should be working together with generic companies to enable these wonderful products to be made available to people in India and South Africa as quickly as possible. Obviously the brand name pharmaceutical companies are entitled to earn their profits. We in the west will have to pay more for the same drugs than people will in South Africa and India. There is no choice if we want to save lives.

Q Today it was announced that the National AIDS Trust won the trial against NHS England to fund PrEP, do you think that is the way forward for other countries as well? 
Oh yes. I think there is absolutely no doubt we have to move in this direction.

Q Finally, where do you see this field of research going in the next 10 years? Are there any particular areas where further research is needed?

I think the most important thing we have to do is to find a cure for HIV. Drugs are very expensive across the board and every year there are more people who are getting infected with HIV. Even though I said generic companies have a huge role to play in ensuring that the best drugs become available in low- and middle-income countries, the fact is that most people in these settings cannot even afford the cost of the generic version of these drugs. It is up to the rich countries of the world to step in and help the poorer countries pay these costs. However, as every year goes by, the costs keep rising because we have both done such a great job at saving people's lives and at the same time the numbers of new cases keep increasing
- this means that total costs of providing drugs to people in developing countries is increasing. This is a costly item for the world so, therefore, who is going to pay? This all creates new pressure and rationale to make sure we find a cure for HIV and hopefully that is going happen soon.

\section{Disclaimer}

The opinions expressed in this interview are those of the interviewee and do not necessarily reflect the views of Future Medicine Ltd.

Financial \& competing interests disclosure

The author has no relevant affiliations or financial involvement with any organization or entity with a financial interest in or financial conflict with the subject matter or materials discussed in the manuscript. This includes employment, consultancies, honoraria, stock ownership or options, expert testimony, grants or patents received or pending, or royalties.

No writing assistance was utilized in the production of this manuscript. 